\title{
CONCENTRAÇÃO DAS EXPORTAÇÕES NO MERCADO INTERNACIONAL DE MADEIRA SERRADA ${ }^{1}$
}

Rommel Noce ${ }^{2}$, Márcio Lopes da Silva ${ }^{3}$, Rosa Maria Miranda Armond Carvalho ${ }^{2}$ e Thelma Shirlen Soares²

\begin{abstract}
RESUMO - Este trabalho objetivou verificar a concentração do mercado internacional de madeira serrada, por meio dos índices de concentração e desigualdade de mercado e das estruturas de classificações de mercado. Utilizou-se como indicador a exportação de 154 diferentes nações nos anos de 1997 e 1999, sendo constatadas a alta concentração e desigualdade do mercado internacional de madeira serrada e a evolução desses parâmetros no período analisado.
\end{abstract}

Palavras-chave: Concentração de mercado, mercado internacional e madeira serrada.

\section{CONCENTRATION OF THE EXPORTS IN THE INTERNATIONAL MARKET OF SAWN WOOD}

\begin{abstract}
The objective of this study was to analyze the concentration of the international market of sawn wood. Concentration and market inequality indexes and structures of market classifications were used. The base of information was the exportation of 154 different nations in 1997 and 1999. A high concentration and inequality of the sawn wood international market and the evolution of these parameters in the analyzed period, was found.
\end{abstract}

Key words: Market concentration, international market, sawn wood.

\section{INTRODUÇÃO}

Ao observar o contexto atual, verificou-se que a atividade florestal se intensificou em todo o mundo, o que se pode confirmar através do crescente comércio de produtos florestais entre diferentes nações e pelo interesse renovado de diversas organizações pelas florestas.

O crescente destaque do setor florestal para a economia brasileira mostra-se no PIB florestal próximo a US\$ 21 bilhões (4\% do total), com US\$ 5,4 bilhões ( $10 \%$ do total) em exportações no ano de 2003 . Vale ressaltar que o setor desempenha importante papel socioeconômico, gerando dois milhões de empregos (diretos e indiretos), recolhendo em torno de US\$ 2 bilhões anuais de impostos, consumindo em torno de 300 milhões de $\mathrm{m}^{3}$ ano de madeira (nativa + plantada) (SBS, 2004).

Segundo Ângelo et al. (1998), nesse contexto a produção e o comércio de madeira ocupam posição de destaque, sendo importante analisar o mercado internacional de madeira, tendo em vista a competitividade.

A desaceleração da economia em mercados

\footnotetext{
${ }^{1}$ Recebido em 20.12.2002 e aceito para publicação em 20.04.2005.

${ }^{2}$ Programa de Pós-Graduação em Ciência Florestal da Universidade Federal de Viçosa, Viçosa-MG.

${ }^{3}$ Departamento de Engenharia Florestal da Universidade Federal de Viçosa. Viçosa-MG. E-mail: <marlosil@ ufv.br>.
} 
tradicionais como EUA e União Européia reflete-se na redução do índice de crescimento do comércio mundial. Assim, as empresas brasileiras buscam mercados alternativos como Rússia, China, África do Sul e Emirados Árabes, incentivadas pela recessão dos principais pólos de exportação e como decorrência logística da globalização (De OLHO..., 2001).

A concentração industrial é um dos principais determinantes estruturais da competição. Afeta as estratégias adotadas pelas firmas participantes, a economia de escala, o tamanho e o crescimento do mercado, além das condições de entrada. Em níveis elevados, a concentração industrial pode prejudicar a alocação eficiente de recursos (KON, 1994), de forma que este estudo tem por objetivo geral medir a concentração do mercado internacional de madeira serrada. Especificamente, busca estimar os índices de concentração e de desigualdade e a classificação do mercado.

\section{MATERIAL E MÉTODOS}

Os dados utilizados neste estudo foram os valores das exportações (em US\$1.000,00) de madeira serrada de conífera e folhosas para 154 países, nos anos de 1997 e 1999, os quais foram extraídos do banco de dados da FAO (2002).

\section{1. Índices de concentração}

Os índices utilizados correspondem a medidas que permitem comparar a evolução do grau de concentração no tempo e entre nações. Assim, a concentração de mercado foi verificada, conforme proposto por Kon (1994), através dos seguintes índices:

a) Índice de Herfindahl-Hirschman: definido pela soma dos quadrados da participação de cada nação no mercado internacional de madeira serrada. Este índice considera a participação de todas as nações, de forma que aumenta à medida que intensifica a concentração. É definido por:

$$
H=\sum_{i=1}^{n} P_{i}^{2}
$$

em que:

$$
\begin{aligned}
\mathrm{H}= & \text { índice de Herfindahl; e } \\
\mathrm{P}_{\mathrm{i}}= & \text { participação porcentual da nação i no total } \\
& \text { das exportações. }
\end{aligned}
$$

R. Árvore, Viçosa-MG, v.29, n.3, p.431-437, 2005
A situação de monopólio apresenta o valor máximo de 1, enquanto para participação igualitária indica o valor de $1 / \mathrm{n}$, sendo n o número de nações participantes (SILVA, 2003).

b) Índice de Joly: este índice considera o tamanho absoluto de cada uma das nações incluídas no mercado e também todas as nações envolvidas, apresentando valores maiores quanto maior a concentração observada. É definido por:

$$
J=\frac{\sum_{i=1}^{n}\left(X_{i}\right)^{2}}{\left(\sum_{i=1}^{n} X_{i}^{2}\right)}
$$

em que:

$\mathrm{J}=$ índice de Joly; e

$\mathrm{X}_{\mathrm{i}}=$ valor total das exportações da nação $\mathrm{i}$.

c) Coeficiente de entropia: determina o grau de incerteza no mercado, de forma que, quanto maior a incerteza de manutenção das vendas, maior o valor de E. Representa o inverso da concentração, ou seja, quanto menor seu valor, mais concentrado se apresenta o mercado. É expresso por:

$$
E=\sum_{i=1}^{n} P_{i} \times \ln \left(\frac{1}{P_{i}}\right)
$$

em que:

$$
\mathrm{E}=\text { índice de entropia de Theil; }
$$

$\mathrm{P}_{\mathrm{i}}=$ participação porcentual da nação i no total das exportações; e

$\ln =\log$ aritmo neperiano.

Segundo Resende (1994), essa medida representa o inverso da concentração, ou seja, o valor diminui quando a concentração aumenta. Pode ser utilizada para determinar o grau de incerteza de um mercado, no sentido de que, quanto maior o número de concorrentes e a incerteza de uma empresa manter um cliente, maior o valor de E.

\subsection{Medidas de desigualdade}

A desigualdade do mercado entre as nações foi estimada através do índice de Gini: 


$$
G=1-\frac{\sum_{i=1}^{n}\left(C_{i j}+C_{i}\right)}{n}
$$

em que:

$$
\begin{aligned}
& \mathrm{G}=\text { índice de Gini; } \\
& \mathrm{n}=\text { número de nações; } \\
& \mathrm{C}_{\mathrm{ij}}=\begin{array}{l}
\text { participação acumulativa nas exportações } \\
\text { em ordem crescente; } \mathrm{e}
\end{array} \\
& \mathrm{C}_{\mathrm{i}}=\text { participação da nação } \mathrm{i} .
\end{aligned}
$$

Hoffmann (1980) e Resende (1994) relataram que o índice de Gini assume valores entre "zero" (ausência de concentração/igualdade absoluta entre todos os componentes do universo examinado) e " 1 ", (concentração absoluta/desigualdade total). Para efeito de classificação da concentração, medida pelo índice de Gini, utilizou-se a escala apresentada no Quadro 1.

\subsection{Classificação dos mercados}

Neste estudo, a classificação do mercado internacional de madeira serrada foi realizada segundo as definições de Caves (1982), conforme sumarizado no Quadro 2.

Quanto à concentração, o mercado internacional de madeira serrada foi caracterizado conforme Bain (1959):

- Concentração extremamente alta: participação de poucas nações com as exportações concentradas em três ou quatro nações.

- Concentração muito alta: exportações concentradas em três ou quatro nações com um número relativamente maior de nações participantes.

Quadro 1 - Classificação da desigualdade pelo índice de Gini Table 1 - Inequality classification by Gini index

\begin{tabular}{lc}
\hline \multicolumn{2}{c}{ Interpretação do Índice de Gini } \\
\hline Valor do Índice Gini & Desigualdade do Mercado \\
\hline $0,101-0,250$ & Nula a fraca \\
$0,251-0,500$ & Fraca a média \\
$0,501-0,700$ & Média a forte \\
$0,701-0,900$ & Forte a muito forte \\
$0,901-1,000$ & Muito forte a absoluta \\
\hline
\end{tabular}

Quadro 2 - Classificação do mercado Table 2-Market classification

\begin{tabular}{lccc}
\hline Estruturas de Mercado & \multicolumn{3}{c}{$\begin{array}{c}\text { Participação das Nações nas } \\
\text { Exportações Mundiais }\end{array}$} \\
\cline { 2 - 4 } & 4 maiores & 8 maiores & 20 maiores \\
\hline Oligopólio I & $50 \%$ & $75 \%$ \\
Oligopólio II & $33 \%$ & $75 \%$ \\
Indústria não-concentrada & & $<33 \%$ & \\
Indústria competitiva & $<10 \%$ & & \\
\hline
\end{tabular}
Fonte: Caves (1982).

- Concentração alta: oito maiores nações exportadoras respondendo por 70 a $85 \%$ do valor exportado e as quatro maiores nações exportadoras respondendo por 50 a $65 \%$, com um número de nações participantes relativamente alto.

- Concentração baixa/moderada: oito principais nações exportadoras são responsáveis por 45 a $70 \%$ das exportações com as quatro maiores nações exportadoras respondendo por 35 a $50 \%$.

- Baixo grau de oligopólio: oito maiores nações exportadoras com participação inferior a $45 \%$ do mercado internacional e a parcela das quatro maiores nações exportadoras inferior a $35 \%$.

- Atomismo: elevado número de nações participa do mercado e a participação das quatro maiores nações exportadoras não supera $10 \%$.

Interpretou-se, também, a classificação do mercado internacional quanto à concentração, segundo as proposições de Gregory (1987), apresentadas no Quadro 3.

\section{RESULTADOS E DISCUSSÃO}

\subsection{Concentração do mercado}

Observa-se no Quadro 4 que os índices de Herfindahl-Hirschman e Joly indicam um grau mais elevado de concentração no mercado internacional de coníferas, em comparação com o de folhosas, estando o mercado total das duas em posição intermediária.

Quadro 3 - Grau de concentração do mercado Table 3-Degree of market concentration

\begin{tabular}{lc}
\hline Caracterização & $\begin{array}{r}\text { Participação das } 4 \text { Maiores } \\
\text { Nações Exportadoras }\end{array}$ \\
\hline Extremamente concentrado & $75 \%$ \\
Altamente concentrado & $50 \%$ a $74 \%$ \\
Moderadamente concentrado & $25 \%$ a $49 \%$ \\
Relativamente pouco concentrado & $24 \%$ \\
\hline
\end{tabular}
Fonte: Gregory (1987).

R. Árvore, Viçosa-MG, v.29, n.3, p.431-437, 2005 
Quadro 4 - Medidas de concentração para o mercado internacional de madeira serrada Table 4-Concentration indexes for the sawn wood international market

\begin{tabular}{|c|c|c|c|c|c|c|}
\hline \multirow[t]{2}{*}{ Índices } & \multicolumn{3}{|c|}{1997} & \multicolumn{3}{|c|}{1999} \\
\hline & Folhosas & Coníferas & Total & Folhosas & Coníferas & Total \\
\hline Herfindahl-Hirschman & 0,095 & 0,246 & 0,159 & 0,086 & 0,258 & 0,156 \\
\hline Joly & 0,095 & 0,246 & 0,159 & 0,086 & 0,258 & 0,156 \\
\hline Coeficiente de entropia & 1,328 & 0,944 & 1,176 & 1,362 & 0,931 & 1,182 \\
\hline
\end{tabular}

De forma análoga, o coeficiente de entropia assinala para uma incerteza maior no mercado de folhosas em comparação com o de coníferas.

Analisando as evoluções nos índices de concentração do ano de 1997 para 1999, notaram-se aumento da incerteza e redução da concentração em $9,47 \%$ para o mercado de folhosas e incremento da concentração e diminuição da incerteza em $4,88 \%$ para o mercado de coníferas.

\subsection{Desigualdade do mercado}

A desigualdade medida através do índice de Gini é considerada muito forte a absoluta. Para o mercado de coníferas, folhosas e total destas, nos anos de 1997 e 1999, os valores obtidos estão entre 0,900 e 1,000 (Quadro 5).

\subsection{Classificação do mercado}

Analisando os Quadros 6 e 7, observa-se que,

Quadro 5 - Índice de Gini

Table 5 - Gini index

\begin{tabular}{lcc}
\hline Categoria & \multicolumn{2}{c}{ Ano } \\
\cline { 2 - 2 } & 1997 & 1999 \\
\hline Folhosas & 0,926 & 0,920 \\
Coníferas & 0,956 & 0,954 \\
Total & 0,943 & 0,940 \\
\hline
\end{tabular}

conforme Caves (1982), os mercados de coníferas, folhosas e ambos totalizados apresentam a mesma estrutura, ou seja, "Oligopólio I", caracterizado quando as oito maiores nações exportadoras detêm mais de $50 \%$ do mercado, e as 20 maiores nações exportadoras respondem por $70 \%$.

Considerando a classificação de Gregory (1987), verificou-se que o mercado apresenta-se "altamente concentrado" para coníferas, folhosas e o total exportado das duas, tanto no ano de 1997 quanto no de 1999. Segundo esse autor, o mercado caracteriza-se dessa forma quando as quatro principais nações respondem por 50 a $74 \%$ das exportações.

Já as proposições de Bain (1959), em razão do observado nos índices de concentração, indicaram para uma maior concentração no mercado de coníferas, apresentando concentração "muito alta" diante do mercado de folhosas que se mostra com concentração entre "baixa/moderada" e "alta", o total das exportações apresenta-se com concentração "alta", para o ano de 1997. A única alteração de 1997 para 1999 ocorreu no mercado de folhosas, que passa a apresentar concentração "baixa/moderada".

Nos Quadros 8, 9 e 10 que seguem, apresentamse as participações das 20 maiores nações exportadoras de coníferas, folhosas e totais respectivamente, no mercado internacional.

Quadro 6 - Participação porcentual das principais nações exportadoras no mercado internacional Table 6-Participation of the nation's exporters in the international market

\begin{tabular}{|c|c|c|c|c|c|c|}
\hline \multirow[t]{2}{*}{ Tipo de Madeira } & \multicolumn{3}{|c|}{1997} & \multicolumn{3}{|c|}{1999} \\
\hline & 4 maiores & 8 maiores & 20 maiores & 4 maiores & 8 maiores & 20 maiores \\
\hline Conífera & 73 & 85 & 96 & 72 & 85 & 96 \\
\hline Folhosas & 54 & 69 & 85 & 50 & 65 & 84 \\
\hline Total & 61 & 77 & 90 & 60 & 74 & 89 \\
\hline
\end{tabular}

R. Árvore, Viçosa-MG, v.29, n.3, p.431-437, 2005 
Quadro 7 - Classificação do mercado internacional de madeira serrada

Table 7 - Classification of the international market of sawn wood

\begin{tabular}{|c|c|c|c|c|c|c|}
\hline \multirow[t]{2}{*}{ Autor } & \multicolumn{3}{|c|}{1997} & \multicolumn{3}{|c|}{1999} \\
\hline & Conífera & Folhosas & Total & Conífera & Folhosas & Total \\
\hline Caves (1982) & Oligopólio I & Oligopólio I & Oligopólio I & Oligopólio I & Oligopólio I & Oligopólio I \\
\hline Bain (1959) & Muito alta & $\begin{array}{c}\text { Baixa a } \\
\text { moderada/Alta }\end{array}$ & Alta & Muito alta & Baixa a moderada & Alta \\
\hline Gregory (1987) & $\begin{array}{c}\text { Altamente } \\
\text { concentrado }\end{array}$ & $\begin{array}{l}\text { Altamente } \\
\text { concentrado }\end{array}$ & $\begin{array}{l}\text { Altamente } \\
\text { concentrado }\end{array}$ & $\begin{array}{l}\text { Altamente } \\
\text { concentrado }\end{array}$ & $\begin{array}{c}\text { Altamente } \\
\text { concentrado }\end{array}$ & $\begin{array}{l}\text { Altamente } \\
\text { concentrado }\end{array}$ \\
\hline
\end{tabular}

Quadro 8 - Participação das 20 principais nações exportadoras de madeira serrada - Coníferas

Table 8 -Participation of the 20 main export nations of sawn wood-Softwood

\begin{tabular}{|c|c|c|c|}
\hline \multicolumn{2}{|c|}{1997} & \multicolumn{2}{|l|}{1999} \\
\hline Países & Participação (\%) & Países & Participação (\%) \\
\hline$\overline{\text { Canadá }}$ & 46,372 & Canadá & 48,098 \\
\hline Suécia & 12,217 & Suécia & 11,123 \\
\hline Finlândia & 8,093 & Finlândia & 8,009 \\
\hline EUA & 6,398 & Áustria & 4,997 \\
\hline Áustria & 4,411 & EUA & 4,569 \\
\hline Rússia & 3,491 & Rússia & 3,909 \\
\hline Chile & 2,335 & Alemanha & 2,132 \\
\hline Alemanha & 2,032 & Letônia & 2,039 \\
\hline Nova Zelândia & 1,514 & Nova Zelândia & 1,846 \\
\hline Letônia & 1,456 & Chile & 1,577 \\
\hline México & 1,065 & Brasil & 1,472 \\
\hline República do Cazaquistão & 1,028 & República do Cazaquistão & 1,188 \\
\hline Brasil & 1,003 & Romênia & 0,994 \\
\hline Noruega & 0,812 & Noruega & 0,778 \\
\hline Romênia & 0,636 & Estônia & 0,766 \\
\hline Lituânia & 0,628 & Polônia & 0,611 \\
\hline Polônia & 0,588 & Lituânia & 0,482 \\
\hline Estônia & 0,582 & França & 0,479 \\
\hline China & 0,499 & Bélgica & 0,436 \\
\hline França & 0,478 & Eslováquia & 0,39 \\
\hline Resto do mundo & 4,362 & Resto do mundo & 4,101 \\
\hline
\end{tabular}

Quadro 9 - Participação porcentual das 20 principais nações exportadoras de madeira serrada - Folhosas Table 9 - Percentage participation of the 20 main export nations of sawn wood-Hardwood

\begin{tabular}{|c|c|c|c|}
\hline \multicolumn{2}{|c|}{1997} & \multicolumn{2}{|c|}{1999} \\
\hline Países & Participação (\%) & Países & Participação (\%) \\
\hline$\overline{\text { EUA }}$ & 21,072 & EUA & 20,643 \\
\hline Malásia & 17,180 & Malásia & 15,108 \\
\hline Indonésia & 9,042 & Indonésia & 7,679 \\
\hline Canadá & 6,314 & Canadá & 6,794 \\
\hline Brasil & 4,768 & Brasil & 4,935 \\
\hline China & 4,214 & Alemanha & 4,453 \\
\hline França & 3,217 & França & 2,935 \\
\hline Alemanha & 2,855 & Camarões & 2,875 \\
\hline Itália & 2,475 & Costa do Marfim & 2,858 \\
\hline Costa do Marfim & 1,927 & China & 2,540 \\
\hline Croácia & 1,655 & Itália & 1,917 \\
\hline Gana & 1,633 & Romênia & 1,872 \\
\hline Romênia & 1,341 & Croácia & 1,734 \\
\hline Cingapura & 1,313 & Gana & 1,652 \\
\hline Camarões & 1,296 & Polônia & 1,144 \\
\hline Países Baixos & 1,112 & Bélgica & 1,123 \\
\hline Bélgica & 1,044 & Países Baixos & 1,033 \\
\hline Polônia & 1,027 & Finlândia & 0,970 \\
\hline Bolívia & 0,891 & Tailândia & 0,966 \\
\hline Tailândia & 0,883 & Hungria & 0,962 \\
\hline Resto do mundo & 14,741 & Resto do mundo & 15,807 \\
\hline
\end{tabular}


Quadro 10 - Participação porcentual das 20 principais nações exportadoras de madeira serrada - Totais Table 10 - Percentage participation of the 20 main export nations of sawn wood-Total

\begin{tabular}{|c|c|c|c|}
\hline \multicolumn{2}{|c|}{1997} & \multicolumn{2}{|c|}{1999} \\
\hline Países & Participação \% & Países & Participação \% \\
\hline$\overline{\text { Canadá }}$ & 35,514 & Canadá & 36,495 \\
\hline EUA & 10,375 & EUA & 9,084 \\
\hline Suécia & 9,112 & Suécia & 8,116 \\
\hline Finlândia & 6,006 & Finlândia & 6,032 \\
\hline Malásia & 4,813 & Malásia & 4,327 \\
\hline Áustria & 3,388 & Áustria & 3,818 \\
\hline Indonésia & 2,752 & Rússia & 2,972 \\
\hline Rússia & 2,649 & Alemanha & 2,784 \\
\hline Alemanha & 2,255 & Brasil & 2,445 \\
\hline Brasil & 2,023 & Indonésia & 2,415 \\
\hline Chile & 1,758 & Letônia & 1,650 \\
\hline China & 1,506 & Nova Zelândia & 1,391 \\
\hline França & 1,220 & Romênia & 1,240 \\
\hline Letônia & 1,173 & Chile & 1,222 \\
\hline Nova Zelândia & 1,138 & França & 1,169 \\
\hline Itália & 0,899 & China & 0,948 \\
\hline Romênia & 0,827 & República Tcheca & 0,926 \\
\hline México & 0,807 & Camarões & 0,808 \\
\hline República do Cazaquistão & 0,803 & Costa do Marfim & 0,807 \\
\hline Polônia & 0,707 & Polônia & 0,761 \\
\hline$\underline{\text { Resto do Mundo }}$ & 10,275 & Resto do Mundo & 10,590 \\
\hline
\end{tabular}

\section{CONCLUSÕES}

- Os índices Herfindahl-Hirschman, Joly e o Coeficiente de Entropia indicam uma concentração mais acentuada no mercado internacional de coníferas do que no de folhosas. Ocorreu uma diminuição da concentração no mercado de folhosas diante da intensificação desta no mercado de coníferas, no período de 1997 a 1999.

- Os mercados internacionais, tanto de coníferas quanto de folhosas, apresentam-se com desigualdade de muito forte a absoluta.

- A estrutura do mercado internacional que se observa, tanto para coníferas quanto para folhosas, é de "Oligopólio I".

- Aplicando as proposições de Gregory (1987), tanto o mercado de coníferas quanto o de folhosas mostram-se "altamente concentrados".

- Aplicando as proposições de Bain (1959), o mercado internacional de coníferas mostra-se com concentração "muito alta", tanto no ano de 1997 quanto em 1999. O mercado de folhosas evolui de uma posição intermediária entre "alta" e "baixa/moderada" para "baixa/moderada".

- A estrutura oligopolizada, somada à alta concentração e a forte desigualdade observadas, tanto no mercado de coníferas quanto de folhosas, influi diretamente na competição desses mercados, podendo levar as principais nações a uma conduta interdependente, no que se refere a preços e produção, prejudicando, dessa forma, a alocação eficiente de recursos.

\section{REFERÊNCIAS BIBLIOGRÁFICAS}

ANGELO, H.; HOSOKAWA, T. R.; BERGER, R. O Brasil no mercado internacional de madeiras tropicais. Revista Árvore, v. 22, n. 4, p. 483494, 1998.

B AIN, J. Industrial organization. New York: John Wiley and Sons, 1959. 274p.

CAVES, R. E. American industry, structure, conduct and performance. Englewood Cliffs: Prentice Hall, 1982. 306 p.

FOOD AND AGRICULTURE ORGANIZATION OF THE UNITED NATIONS - FAO. FAO

statistical databases. Disponível em: <http:// apps2.fao.org/TradeFlow/Fytf_Q-e.htm>. Acesso em: 15 julho 2002 .

GREGORY, G. R. Resource economics for foresters. New York: John Wiley \& Sons, 1987. 477 p. 
HOFFMANN, R. Estatística para

economistas. São Paulo: Biblioteca Pioneira de Ciências Sociais, 1980. 379p.

KON, A. Economia industrial. São Paulo: Nobel, 1994. 212p.

RESENDE, M. Medidas de concentração industrial: uma resenha. Análise econômica, v.11, p. 24-33, 1994.

DE OLHO em novos mercados. Revista da Madeira, v.11, n. 61, p. 6-8, 2001.
SOCIEDADE BRASILEIRADE SILVICULTURASBS. Setor florestal brasileiro. Disponível em: <http://www.sbs.org.br/estatisticas.htm>. Acesso em: 18 julho 2004.

SILVA, F. C. A. et al. Migração rural e estrutura agrária no oeste catarinense. 2. ed. Florianópolis: InstitutoCepa, 2003. 99p.

SILVA, Z. A. G. P. G. Análise econômica da concentração no uso de madeira tropical pelo setor de marcenarias de Rio Branco, estado do Acre, 1996. Scientia Forestalis, n. 64, p. 48-58, 2003. 